\title{
Correction to: Late spinal infections following posterior spinal fusion in pediatric deformities: treatment using single-stage titanium implant exchange
}

\author{
Bijan Ameri ${ }^{1} \cdot$ Harry L. Shufflebarger ${ }^{2}$. Blaze Emerson ${ }^{1} \cdot$ Jahangir Asghar $^{3} \cdot$ Stephen G. George $^{3}$.
} Subaraman Ramchandran ${ }^{4}$ (D)

Published online: 26 February 2021

(c) Scoliosis Research Society 2021

\section{Correction to: Spine Deformity https://doi.org/10.1007/s43390-020-00266-3}

The original version of this article unfortunately contained a mistake. The given name and the family name of the author "Blaze Emerson" were interchanged.

The original article has been corrected.

The original article can be found online at https://doi.org/10.1007/ s43390-020-00266-3.

\section{Subaraman Ramchandran}

subbu_gsmc@yahoo.co.in

1 Department of Orthopedic Surgery At Broward Health Medical Center, Fort Lauderdale, FL, USA

2 Paley Orthopedic and Spine Institute At St. Mary Children's Hospital, West Palm Beach, FL, USA

3 Cantor Spine Institute, Fort Lauderdale, FL, USA

4 Department of Orthopedic Surgery, Center for Spinal Disorders At Nicklaus Children's Hospital, Miami, FL 33155, USA 